\title{
AVALIAÇÃO DA QUALIDADE DO QUEIJO “COALHO” ARTESANAL FABRICADO EM JUCATI - PE
}

João Rufino de Freitas Filho ${ }^{1}$ João Sales de Souza Filho ${ }^{2}$ Heraldo Bezerra de Oliveira ${ }^{3}$ José Henrique Berto Angelo ${ }^{4}$ Janieire Dorlamis Cordeiro Bezerra ${ }^{5}$

\section{RESUMO}

Este trabalho foi desenvolvido para avaliar aspectos higiênico-sanitários da produção artesanal de queijo coalho em pequenas unidades de produção no município de Jucati (PE) e também fornecer orientação aos produtores quanto à importância da higiene para obtenção de um produto de qualidade. As coletas foram realizadas mensalmente, durante seis meses, em seis propriedades. Analisaram-se amostras de leite, queijo e utensílios utilizados em diferentes etapas da linha de produção. Constatou-se a inadequação do tratamento térmico e das práticas de higiene adotadas para os utensílios. O acompanhamento da produção, orientação aos produtores e análise dos produtos para determinar os agravantes de contaminação são de extrema importância para a garantia da qualidade do produto.

Palavras-chave: Queijo. Qualidade higiênica. Alimento de qualidade.

\footnotetext{
${ }^{1}$ Licenciado em Química, Mestre em Química Orgânica (UFPE), Doutor em Química Orgânica (UFPE), Pósdoutor em Química pela Université Claude Bernard (França), e docente da Universidade Federal Rural de Pernambuco - UFRPE / Unidade Acadêmica de Garanhuns - UAG.

${ }^{2}$ Mestre em Química e Técnico em Química da Unidade Acadêmica de Garanhuns/ UFRPE.

${ }^{3}$ Estudante de Zootecnia da Universidade Federal Rural de Pernambuco/Unidade Acadêmica de Garanhuns.

${ }^{4}$ Estudante de veterinária da Universidade Federal Rural de Pernambuco/Unidade Acadêmica de Garanhuns.

${ }^{5}$ Estudante de Zootecnia da Universidade Federal Rural de Pernambuco/Unidade Acadêmica de Garanhuns.
} 


\title{
EVALUATION OF THE QUALITY OF ARTISANAL “COALHO” CHEESE PRODUCED IN JUCATI CITY - PE
}

\begin{abstract}
This work was performed in order to evaluate the hygienical-sanitary and physical-chemical features of homemade production of coalho cheese in small units of production cheese in small units of production in Jucati (PE) and the orientation to the breeders regarding the importance of hygiene to obtain the quality mark. The collects were performed monthly during six months on properties. We analyzed samples of milk, cheese and utensils used in different stages of the production line. it was the inadequate thermic treatment and hygienic procedures of the utensils. Keeping track of the production, orienting the breeders and analysing the products to determine the aggravating factors of contamination are extremely important to guarantee the quality of the product.
\end{abstract}

Keywords: Cheese. Hygienic quality. Food quality

\section{INTRODUÇÃO}

Os queijos são alimentos derivados do leite, ricos em proteínas de alto valor biológico, cálcio, fósforo, zinco, iodo, selênio, vitaminas e oligoelementos, existindo em todo o mundo mais de 1.000 tipos, feitos a partir de diferentes leites e diferentes processos de produção (LÁCTEA BRASIL, 2006). Segundo BORGES et al. (2003), com o desenvolvimento tecnológico de sua produção, sugiram, em nível nacional, muitas variedades, sendo algumas de expressão regional. Bem aceito e com grande popularidade, o queijo de coalho tem sua produção restrita à região nordestina, sendo encontrado, principalmente, nos Estados do Ceará, Paraíba, Pernambuco e Rio Grande do Norte (AQUINO, 1983). Entende-se por queijo de coalho, o queijo que se obtém por coagulação do leite por meio do coalho ou por outras enzimas coagulantes apropriadas, complementadas ou não pela ação de bactérias lácteas selecionadas, e comercializado normalmente com até 10 (dez) dias de fabricação. É um queijo de média a alta umidade, de massa semi-cozida ou cozida que apresenta um teor de gordura nos sólidos totais variável entre 35,0\% e 60,0\% (BRASIL, 2001a). 
No Nordeste do Brasil, a maior parte da produção de queijo-coalho é obtida em pequenas e médias queijarias, as quais movimentam, mensalmente, algo em torno de 10 milhões de reais, o que sinaliza essa atividade como importante para o âmbito social e econômico da região (PERRY, 2004).

Apesar de sua importância econômica e grande popularidade, a fabricação de queijo de coalho não conta com tecnologia apropriada para a melhoria de sua qualidade. É necessário que o processo tradicional, geralmente artesanal e a partir de leite cru, acompanhe a evolução das técnicas queijeiras mediante modificações já utilizadas na tecnologia de outros queijos nacionais.

A elaboração de queijos constitui uma das mais importantes atividades da indústria de produtos lácteos. Suas técnicas de produção provêm de tradições enraizadas, persistindo até hoje em todas as regiões produtoras. Segundo NASSU et al. (2001), a falta de critérios de qualidade da matéria-prima e das técnicas de processamento permite que o queijo se classifique no mercado de produtos de baixa qualidade, tanto do ponto de vista higiênicosanitário quanto da falta de padronização do produto.

Para se obter um produto saudável e de grande valor nutritivo, é necessário que programas de gestão de segurança de alimentos sejam implantados. As Boas Práticas de Fabricação (BPF) é um programa indispensável quando se trata de qualidade e segurança alimentar. Em virtude do processo de fermentação, a microbiota dos queijos é constituída de microrganismos desejáveis e indesejáveis. A presença de microrganismos desejáveis contribui para as características organolépticas, conservação e condições higiênico-sanitárias do produto. Segundo NETO et al (2004) a presença de microorganismos indesejáveis pode ser resultante de contaminações relacionada à higiene inadequada.

O presente trabalho teve como objetivos avaliar os aspectos higiênico-sanitários e físico-químicos da produção artesanal de queijo coalho em pequenas unidades de produção no município de Jucati (PE) e também fornecer orientação aos produtores quanto à importância da higiene para obtenção de um produto de qualidade.

\section{MATERIAL E MÉTODOS}

O projeto foi realizado no município de Jucati (PE) e o período de desenvolvimento teve duração de 180 dias (maio/2008 a outubro/2008) e foi dividido em dois momentos: I pesquisa de campo e II - pesquisa experimental. 


\subsection{PESQUISA DE CAMPO}

\subsubsection{Atividades desenvolvidas}

2.1.1.1 Escolha das propriedades objeto de estudo

Este estudo foi conduzido para selecionar as propriedades como objeto de estudo. O processo seletivo considerou os seguintes critérios: localização, produção, mercado, comercialização, grau de evolução do ensino e acesso à informação dos proprietários e dos manipuladores (mão-de-obra), tamanho da propriedade etc.

Foram escolhidas seis propriedades como objetos de estudo (A, B, C, D, E e F), das quais, cerca de $78 \%$ fabricam os queijos na pia da cozinha e $22 \%$ em queijarias de fundo de quintal, conforme pode-se observar na figura 1.

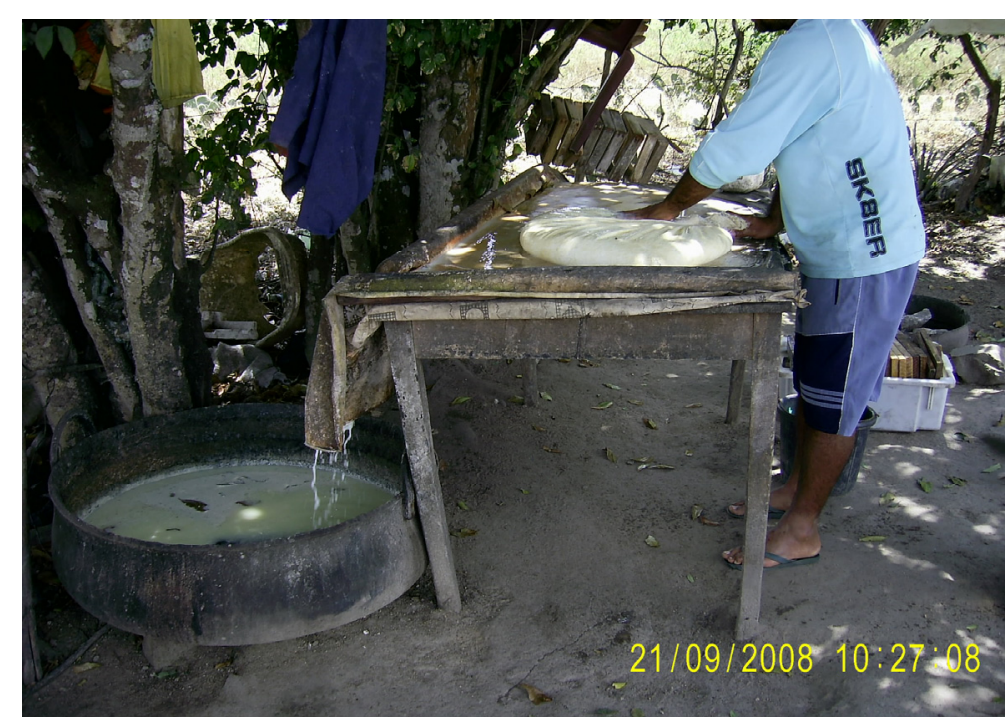

Figura 1 - Queijaria de fundo de quintal

\subsubsection{Elaboração e aplicação de questionário}

O objetivo do questionário foi levantar os dados sócio-econômicos dos produtores de queijos. Os questionários priorizaram a obtenção de dados referentes à:

a) identificação dos produtores de queijo; 
b) desenvolvimento social: grau de evolução do ensino e acesso à informação;

c) desenvolvimento local: tempo de residência, tamanho da propriedade e a adoção de tecnologia;

d) indicativos da composição da renda da família e da propriedade e utilização (tempo) mão-de-obra na propriedade;

e) produção, mercado e comercialização: como é realizada a produção, a venda e a comercialização da produção.

\subsubsection{Visita in lócus}

A visita foi realizada como o objetivo de conhecer as boas práticas higiênicas na produção do queijo coalho e coletar amostra para análise. No momento da coleta, foram observadas e anotadas características na produção do queijo. As anotações foram referentes aos seguintes itens:

a) local da coleta;

b) higiene do local onde o queijo era produzido;

c) embalagens do produto;

d) água utilizada no fabrico;

e) mistura com outros tipos de alimentos;

f) temperatura do local de exposição do produto;

g) identificação na embalagem da data de validade.

Nestas visitas, também foram observadas as boas práticas higiênicas na ordenha, sanidade do rebanho, condições higiênico-sanitárias do estabelecimento, manipulação e acondicionamento do produto e condições higiênicas dos manipuladores do leite usado na fabricação do queijo.

\subsubsection{Elaboração de cartilha e divulgação na comunidade}

Aproveitando os dados dos estudos anteriores, foram elaboradas cartilhas informativas, com o objetivo de conscientizar os produtores e consumidores de queijo coalho quanto à importância das boas práticas higiênicas na produção do queijo. As cartilhas foram distribuídas e divulgadas em eventos científicos. 


\subsubsection{Realização de oficinas temáticas e minicursos}

Estas atividades tiveram como objetivo orientar os produtores sobre a qualidade higiênico-sanitária do queijo coalho, visando oferecer produtos com qualidade para o consumidor. No momento da realização dos minicursos, foram entregues cartilhas informativas com dados do queijo analisado. Optou-se por este procedimento devido à aceitação dos produtores quanto à orientação da prática correta da produção do queijo coalho.

Nos minicursos foram abordados os seguintes temas: a) aspectos de obtenção higiênica do leite e do procedimento de higienização de baldes, latões e locais nos quais seria armazenado; e b) armazenamento do queijo e higienização dos materiais de uso na fabricação e local de produção. Nas oficinas, propõe-se o uso de um detergente alcalino para limpeza de utensílios e distribuiu-se, aos produtores, um material impresso com os procedimentos para obtenção de leite de boa qualidade e queijo de boa qualidade.

\subsection{PESQUISA EXPERIMENTAL}

\subsubsection{Atividades desenvolvidas}

\subsubsection{Coletas de amostras}

As amostras foram coletadas mensalmente no local de produção e transportadas, em caixas isotérmicas com gelo, até o Laboratório de Química da Unidade Acadêmica de Garanhuns (UAG). As amostras foram identificadas como A, B, C, D, E e F.

$\mathrm{O}$ trabalho em laboratório foi conduzido segundo a metodologia descrita por LANARA (1981) e a recomendação constante na Instrução Normativa $n^{\circ} 62$ de 26 de agosto de 2003 do Ministério da Agricultura, Pecuária e Abastecimento.

\subsubsection{Teste de fritura}

O teste de fritura foi realizado com amostras de queijo coalho artesanal. O teste de fritura consistiu em cortar pedaços de queijo coalho com dimensões de $8 \mathrm{~cm}$ x $4 \mathrm{~cm}$ x $1 \mathrm{~cm}$, sem a casca, fritar em ambos os lados, numa frigideira de alumínio, em fogo médio, com 
cerca de 5,0 g de margarina. O tempo de fritura foi de, aproximadamente, 1 minuto e 40 segundos. Foram consideradas aprovadas no teste, as amostras de queijo que não derreteram.

\subsubsection{Avaliação dos parâmetros físico-químicos}

$\mathrm{Na}$ avaliação dos parâmetros físico-químicos, as amostras foram preparadas de acordo com os métodos analíticos oficiais, publicados por LANARA (1981). O teor de umidade foi quantificado pela secagem das amostras em estufa a $105^{\circ} \mathrm{C}$ até peso constante. Determinou-se o teor de cloreto diretamente na amostra, segundo método modificado por FURTADO (1975). A acidez foi determinada pelo o método Dornic; o pH pelo método direto, usando pHmetro; e a gordura foi determinada pelo método volumétrico de GERBER de Van Gulik para queijo.

\subsubsection{Análises microbiológicas}

No laboratório, foram adicionados $1,0 \mathrm{~g}$ de queijo de diferentes propriedades, misturadas com água destilada, em tubos de ensaios diferentes. Em cada tubo foi colocado um pedaço de algodão molhado de azul de bromotimol, sem encostá-lo no líquido. O sistema foi fechado com uma rolha. Após 24 horas foi verificado se houve a presença de material estranho no interior do produto, assim como odor e/ou aparência estranha.

De cada amostra de queijo, retirou-se assepticamente 25 gramas do produto que foram transferidas para um frasco previamente esterilizado e tarado em balança, e foram posteriormente adicionados $225 \mathrm{ml}$ de solução de citrato de sódio 2\% estéril. Amostra e diluente foram homogeneizados, a fim de obter a diluição inicial $\left(10^{-1}\right)$, seguida de diluições decimais, até a diluição $10^{-4}$. Foi utilizada a técnica do número mais provável (NMP.g ${ }^{-1}$ ), conforme protocolo recomendado por SILVA et al. (2001). Para o enriquecimento primário utilizou-se caldo lauril sulfato triptose (LST) e para a confirmação caldo E. coli (E.C.) a $45^{\circ} \mathrm{C}$.

Todos os tubos continham tubos de Durham para verificar a produção de gás. Os tubos positivos foram comparados à tabela do número mais provável e os resultados registrados como NMP.g ${ }^{-1}$ de coliformes fecais.

\section{RESULTADOS E ANÁLISE}

O trabalho teve início com uma pesquisa de campo onde as perguntas-chave foram as seguintes: a) Como é feito o armazenamento do queijo após fabricação? b) Qual a 
procedência da água usada na fabricação do queijo? c) Como é feito o empacotamento do queijo? As respostas à pergunta a) estão sumarizadas no gráfico 1 abaixo.

O armazenamento dos queijos após a produção, as embalagens utilizadas, as condições higiênicas do local onde se fabricam os queijos e a água utilizada para a fabricação e lavagem dos utensílios também foram analisados.

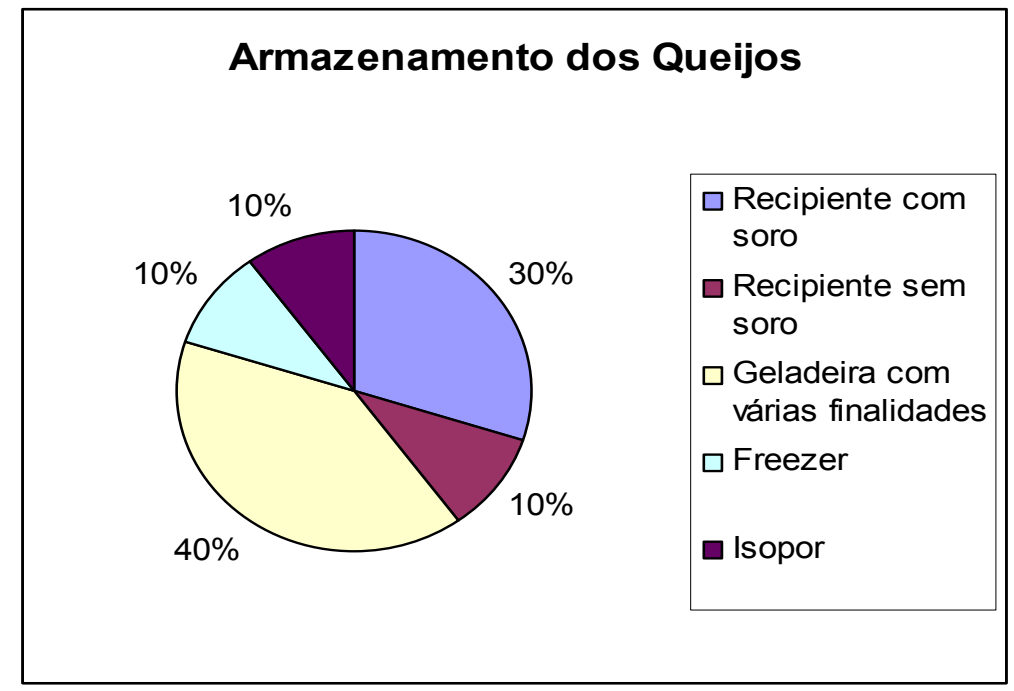

Gráfico 1. Forma de armazenamento do queijo

Conforme o gráfico 2 , cerca de $40 \%$ das propriedades conservam os queijos em geladeiras e $40 \%$ em recipientes diversos. Convém destacar que 30\% das amostras conservadas em recipientes continham soro e $10 \%$ não o continham. Os resultados do tipo de embalagens usadas na comercialização dos queijos estão expressos no gráfico 2.

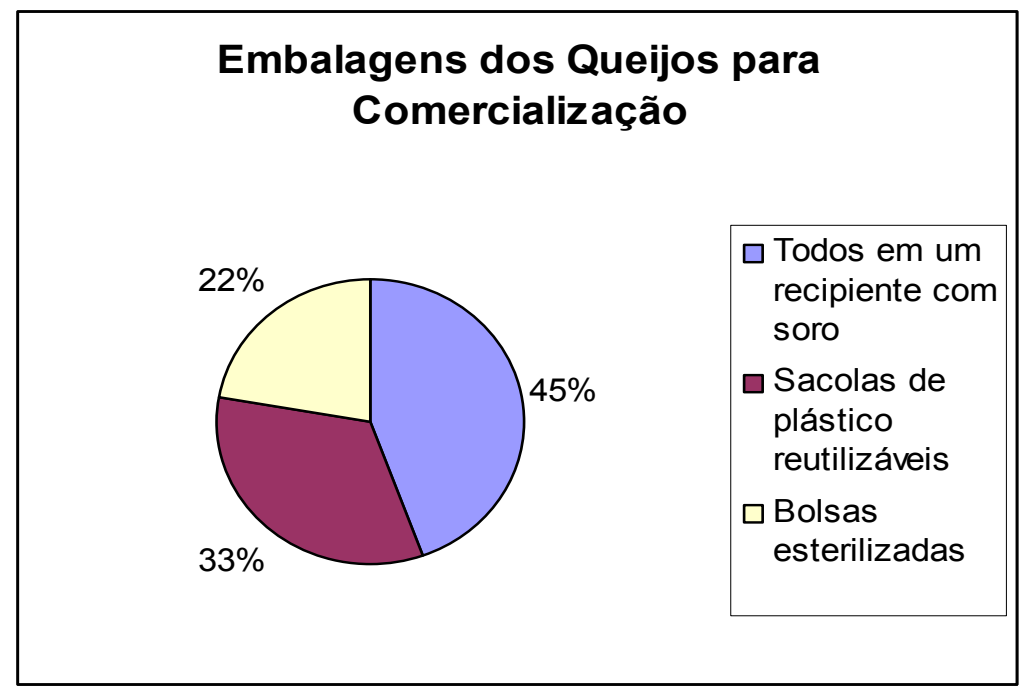

Gráfico 2: Tipos de embalagens usadas 
O local de exposição do produto se mostrou inadequado. Em três propriedades, os queijos ficavam expostos com produtos de outros gêneros, veja detalhe na figura 2.

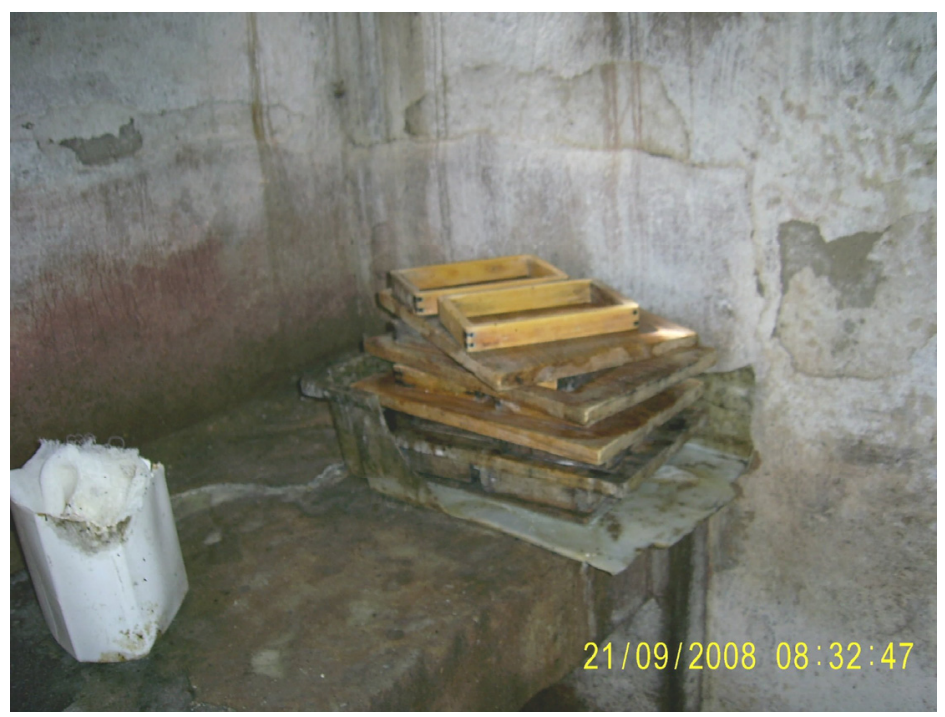

Figura 2. Local de exposição do queijo

O hábito de empacotar os queijos em embalagens representou 55\%, mas apenas $22 \%$ utilizam bolsas esterilizadas, como pode ser observado no gráfico 2 .

A qualidade da água é imprescindível, pois é um dos fatores que mais influenciam na qualidade do queijo. De acordo com dados do gráfico 3, observa-se que $40 \%$ dos produtores utilizam água de barreiro no fabrico do queijo.

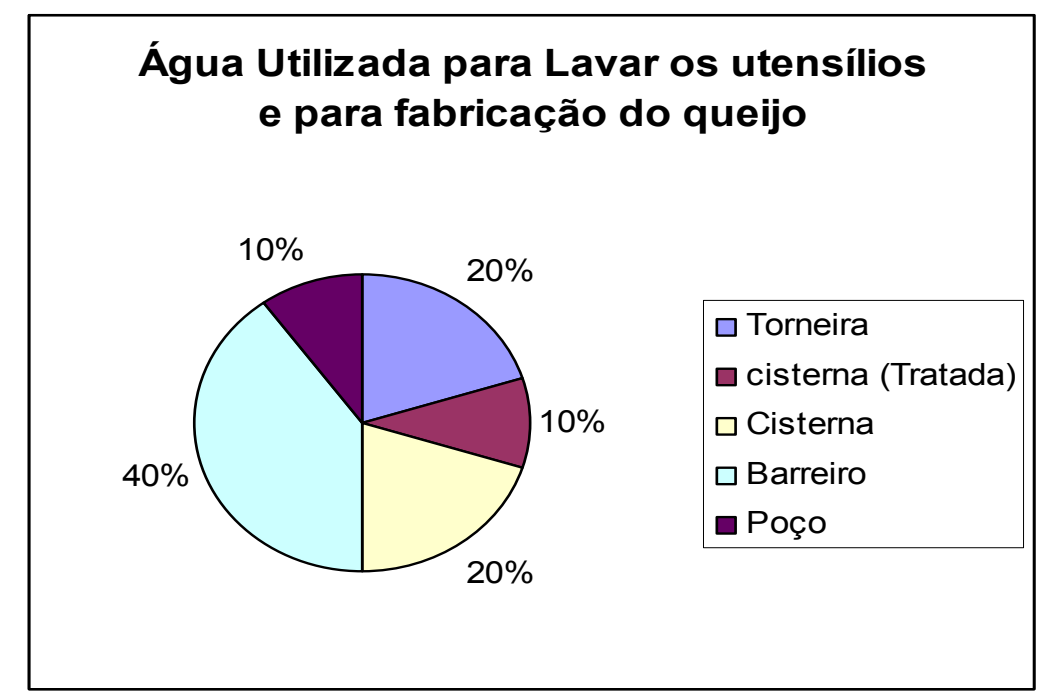

Gráfico 3: Procedência da água usada na fabricação do queijo 
Apesar das exigências para que o leite destinado ao fabrico de queijos seja higienizado por meios mecânicos adequados e submetidos à pasteurização ou tratamento térmico equivalente, em todas as unidades de produção avaliadas, o queijo era produzido a partir de leite não submetido a tratamento térmico, o que aumenta os riscos ao consumidor, sobretudo em dois lotes, onde o queijo era mantido para maturação em ambiente externo a casa, sem nenhuma proteção, conforme figura 3.

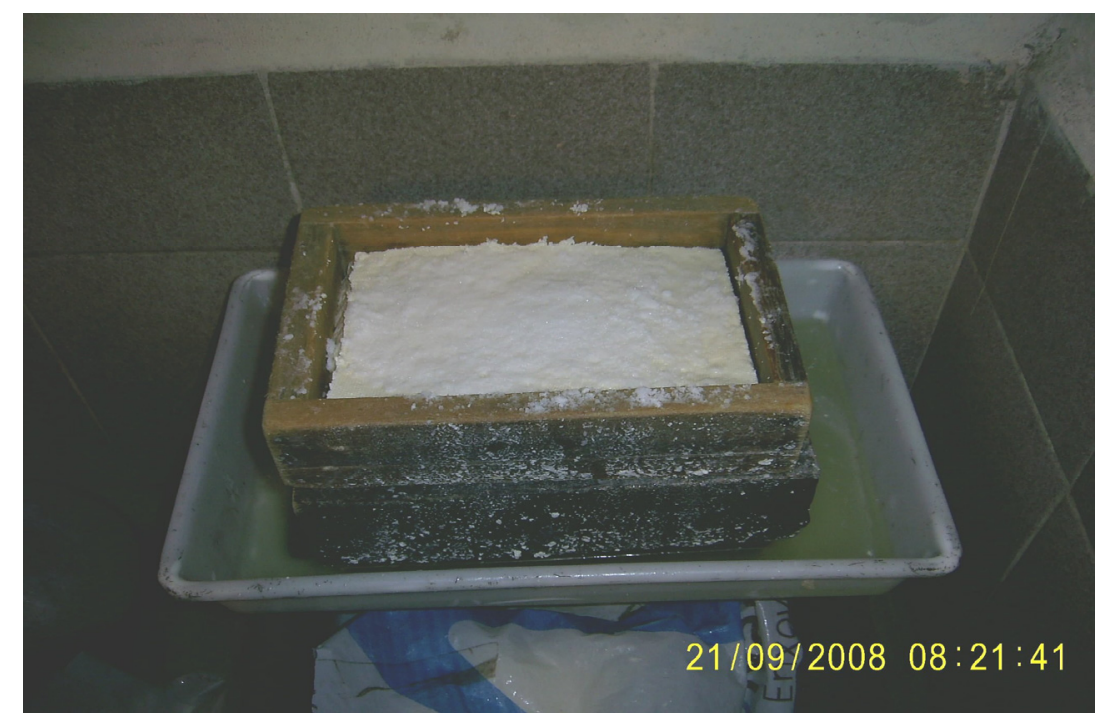

Figura 3. Queijo era mantido para maturação em ambiente externo a casa.

A orientação aos produtores quanto à qualidade higiênico-sanitária do queijo coalho trouxe resultados positivos, vistos nas propriedades A, B e C, de acordo com os resultados das análises do queijo coalho e sua matéria-prima. Cabe a ressalva de que na propriedade $\mathrm{D}$, não foi possível obter sucesso com as orientações devido à falta interesse do proprietário, por esta prática de produção não ser sua fonte de renda, e sim o cultivo de feijão, mandioca, milho etc.

A observação macroscópica das seis amostras de queijo "coalho" produzido artesanalmente demonstrou que não havia nenhum material estranho no interior do alimento, bem como não foi verificado odor e aparência estranhos.

Das seis amostras de queijo coalho analisadas três (50\%) apresentaram crescimento para coliformes fecais, estando três amostras fora dos padrões microbiológicos vigentes segundo a RDC no. 12 do Ministério da Saúde, (BRASIL, 2001b), que é de no máximo $5,0 \times 10^{3} \mathrm{NMP} \cdot \mathrm{g}^{-1}$. As três amostras apresentaram contagem $>1,1 \times 10^{4} \mathrm{NMP} \cdot \mathrm{g}^{-1}$. O número de amostras dentro de intervalos de contagens pode ser observados na Tabela 1. 
Tabela 1. Resultados da análise microbiológica para as amostras A, B, C, D, E e F de queijo de coalho produzido artesanalmente em Jucati, PE

Intervalo de contagem

(NMP. $\left.g^{-1}\right)$

Coliformes fecais $(n=6)$

$\mathrm{N} \%$

$\begin{array}{ccc}10^{2}-10^{3} & 1 & 16,7 \\ 10^{3}-10^{4} & 2 & 33,3 \\ 10^{4}-10^{5} & 3^{*} & 50\end{array}$

*Amostras acima do padrão estabelecido para coliformes fecais $\left(5,0 \times 10^{3} \mathrm{NMP} \cdot \mathrm{g}^{-1}\right)$.

NMP - Número mais Provável

A evidência de coliformes nas análises microbiológicas pode ter vários motivos: a) o leite não foi pasteurizado corretamente; b) o leite foi pasteurizado corretamente, mas a conservação posterior foi inadequada em relação ao tempo e/ou temperatura; c) o leite foi pasteurizado corretamente, mas ocorreu uma recontaminação após a pasteurização. Segundo ISEPON et al. (2003) embalagens contaminadas, mistura acidental de leite cru, operários portadores de doenças, sujidade dos equipamentos e outros são alguns fatores responsáveis pela recontamenação do leite após uma pasteurização correta.

Para melhorar a qualidade dos queijos, foram proporcionados, aos produtores, minicursos e oficinas de Boas Práticas de Fabricação (BPF) que visaram solucionar algumas falhas durante o processamento, tornando-se um método eficiente e eficaz para elaboração de produtos. As oficinas e minicursos tiveram duração de 30 horas. Nas oficinas, os produtores fizeram experimentos simples, usando todas as normas de segurança para obtenção de um produto de qualidade. Durante estas atividades foi entregue para cada produtor cartilhas informativas.

Os resultados mostraram, também, que a obtenção de leite não estava sendo realizado de acordo com as condições higiênicas, o que pode levar a inúmeras contaminações do produto final por microrganismos.

Os resultados encontrados para os parâmetros físico-químicos (umidade, gorduras, $\mathrm{pH}$, acidez e cloreto) para as amostras avaliadas de queijos coalho, indicaram variação entre as amostras analisadas, como pode ser observado na Tabela 2. 
Tabela 2. Resultados da análise físico-química para as amostras A, B, C, D, E e F de queijo de coalho produzido artesanalmente em Jucati, PE

\begin{tabular}{ccccccc}
\hline Análise & Amostra A & Amostra B & Amostra C & Amostra D & Amostra E & Amostra F \\
\hline Umidade(\%) & 51,91 & 54,85 & 46,91 & 55,86 & 55,58 & 60,48 \\
Gordura (\%) & 22,40 & 22,14 & 18,99 & 26,92 & 24,87 & 31,88 \\
pH & 5,80 & 5,47 & 5,85 & 5,27 & 5,67 & 5,70 \\
Acidez (\%) & 0,185 & 0,387 & 0,279 & 0,495 & 0,149 & 0,113 \\
Cloreto (\%) & 3,51 & 3,56 & 2,72 & 2,01 & 3,88 & 2,10 \\
\hline
\end{tabular}

Em relação ao teor de umidade, que variou de $46,91 \%$ a $60,48 \%$, as amostras D, E e F continham um excedente, ou seja, ultrapassaram 55\% de água. A umidade interfere na atividade de água (Wa) e nas ações metabólicas de microorganismos ao longo da maturação, com suas possíveis conseqüências no $\mathrm{pH}$, na textura, no sabor e no aroma. De acordo com os resultados obtidos para teor de umidade, estes podem ser classificados como queijo de "alta umidade", por apresentar valor entre $46,91 \%$ a $60,48 \%$.

Com relação aos teores de gordura obtidos, que variaram de 18,99\% a 31,88\%, percebe-se que as amostras A, B, D, E e F estão entre a faixa $25,0 \%$ e 44,9 \% e a amostra C apresentou valor de 18,99\%, estando abaixo do recomendado.

Os valores de $\mathrm{pH}$ das amostras analisadas variaram de 5,27-5,85\% (tabela 1). Os valores médios mais elevados foram constatados nas amostras B e D.

O valor encontrado para cloreto variou de $2,01 \%$ a $3,88 \%$ nas amostras analisadas. Sabe-se que o sal é utilizado na fabricação de queijos com várias finalidades. Além de contribuir com o sabor, o sal melhora a textura e a aparência do queijo, controla a fermentação lática determinando o nível ideal de acidez, inibe o desenvolvimento de microrganismos indesejáveis e auxilia na expulsão do soro.

O teor de acidez das amostras estava na faixa de 0,11 a $0,49 \%$ de ácido láctico.

$\mathrm{O}$ derretimento do queijo coalho pode ser explicado pelo baixo valor do $\mathrm{pH}$ e alto teor de umidade. MUNCK (2004) reporta que, em pH inferior a 5,7, o queijo coalho derrete e se deforma na presença de calor. 


\section{CONSIDERAÇÕES FINAIS}

O queijo pode ser considerado de má qualidade sanitária, em $50 \%$ das amostras, pois em todas as análises resultou em altas contagens microbianas.

Faz-se necessário uma correção no método de fabricação desse produto, no que diz respeito à higienização, como por exemplo, a pasteurização do leite, o tipo de soro utilizado para a fermentação da massa do queijo e os métodos utilizados na manipulação desse queijo.

Os cuidados na higiene pessoal dos manipuladores deverão ser redobrados, principalmente em relação ao uso de máscaras na hora da filagem e empacotamento e a higienização das mãos.

A água utilizada na filagem deverá ser tratada, pois a presença de coliformes fecais pode estar relacionada à qualidade da água.

As condições de higiene do local de processamento devem ser avaliadas constantemente para se detectarem possíveis focos de contaminação microorgânica.

Evidencia-se a necessidade de severo controle higiênico-sanitária ao longo da linha de produção de queijo. O acompanhamento da produção, orientação aos produtores e análise dos produtos foram relatados em forma de cartilha informativa e entregue aos proprietários e à comunidade em geral.

Os queijos tipo coalho elaborados por pequenos produtores rurais do município de Jucati (PE) apresentam as seguintes características: teor de umidade entre 46,91\% a 60,48\%, $\%$; pH entre 5,27-5,85\%; ácido láctico entre 0,11 e 0,49\%; teor de gordura entre 18,99 e $31,88 \%$; cloreto variou de $2,01 \%$ a $3,88 \%$.

De acordo com os dados obtidos na caracterização físico-química, algumas amostras analisadas atende os padrões para queijo Coalho, segundo a Legislação (BRASIL, 2004).

\section{AGRADECIMENTOS}

Os autores do trabalho agradecem a Fundação de Amparo à Ciência e Tecnologia do Estado de Pernambuco - FACEPE e PRAE/UFRPE pelo suporte financeiro. 


\section{REFERÊNCIAS}

AQUINO, F.T.M. Produção de queijo de coalho no Estado da Paraíba: acompanhamento das características físico-químicas do processamento. 1983. 74f. Dissertação (Mestrado) Universidade Federal da Paraíba, João Pessoa.

BORGES, M.F.; FEITOSA, T.; NASSU, R.T.; MUNIZ, C.R.; AZEVEDO, E.H.F.; FIGUEIREDO, E.A.T. Microrganismos patogênicos e indicadores em queijo de coalho produzido no Estado do Ceará, Brasil. Revista Brasileira CEPPA, v.21, n.1, p.31-40, 2003.

BRASIL. Ministério da Agricultura, Pecuária e Abastecimento. Secretaria de Defesa Agropecuária. Departamento de Inspeção de Produtos de origem Animal. Instrução Normativa $\mathrm{n}^{\mathrm{o}}$ 4, de 01 de março de 2004. ário Oficial da União. . 2004. Disponível em: < http:/www.agricultura.gov.br >. Acessado em: 17/10/2008.

BRASIL. Ministério da Saúde, Agência Nacional de vigilância Sanitária (ANVISA), Resolução - RDC n. 12 de 02/01/2001, Regulamento Técnico sobre os padrões microbiológicos para alimentos. Diário Oficial n. 07-E de 10/01/2001b.

BRASIL. Ministério da Agricultura, Pecuária e Abastecimento. Regulamentos técnicos de identidade e qualidade de manteiga da terra ou manteiga de garrafa, queijo de coalho e queijo de manteiga. Instrução Normativa $n^{\circ} 30$, de 26/06/ 2001. Diário Oficial [da] República Federativa do Brasil, Brasília, DF, 16 jul.2001a, p.13-15.

FURTADO, J. P. Análises bromatológicas. Juiz de Fora: UFJF, 1975. 97 p.

ISEPON, J. S.; SANTOS, P. A.; SILVA, M. A. P. Avaliação microbiológica de queijos minas frescal comercializados na cidade de Ilha Solteira - SP. Revista Higiene Alimentar. v.17, n. 106, p. 89-94. 2003.

LÁCTEA BRASIL. Queijo: Alimento nobre e saudável. Julho de 2006. Disponível em: $<$ www.lacteabrasil.org.br> Acesso em: 13 set 2007. 
LANARA. Métodos analíticos oficiais para controle de produtos de origem animal e seus ingredientes. II - Métodos físicos e químicos. Brasília: Ministério da Agricultura. 1981.

NASSU, R.T; ARAÚJO, R. dos SANTOS; BORGES, M.DE FÁTIMA, LIMA, J.R; MACEDO, B.A; LIMA, M.H.P; BASTOS, M. do SOCORRO R. Diagnóstico das condições de processamento de produtos regionais derivados do leite no Estado do Ceará. Fortaleza: Boletim de pesquisa e desenvolvimento Embrapa Agroindústria Tropical, n.1, p.28, 2001.

MUNCK, A. V. Queijo de Coalho - Princípios básicos da fabricação (Palestra). Revista do Instituto de Laticínios Cândido Tostes, Juiz de Fora, v. 59, n. 339, p. 13-15, 2004.

NETO, L. G. G., VElOSO, F. P., PAIVA, R. M. B., NEVES, M. V. O., FONSECA, L. M., SANTOS, W. L. M. Qualidade físico-química e microbiológica de queijos produzidos no Brasil - Revisão. In: Anais do XXI Congresso Nacional de Laticínios. nº.339, v. 59, p.233236. Juiz de Fora, MG, 2004.

PERRY, K.S.P. Queijos: aspectos químicos, bioquímicos e microbiológicos. Química. Nova, v.27, p.293-300, 2004. 